First Peoples Child \& Family Review

A Journal on Innovation and Best Practices in Aboriginal Child Welfare Administration,

Research, Policy \& Practice

\title{
Learning the Process of Publishing "Voices and Perspectives" of Indigenous Knowledge in the Child Welfare Field
}

\section{Marlyn Bennett}

Volume 1, Number 1, 2004

URI: https://id.erudit.org/iderudit/1069580ar

DOI: https://doi.org/10.7202/1069580ar

See table of contents

Publisher(s)

First Nations Child and Family Caring Society of Canada

ISSN

1708-489X (print)

2293-6610 (digital)

Explore this journal

Cite this article

Bennett, M. (2004). Learning the Process of Publishing "Voices and

Perspectives" of Indigenous Knowledge in the Child Welfare Field. First Peoples

Child \& Family Review, 1(1), 2-4. https://doi.org/10.7202/1069580ar 


\title{
Learning the Process of Publishing "Voices and Perspectives" on Indigenous Knowledge in the Child Welfare Field
}

\author{
Marlyn Bennett, Editor
}

The genesis of this journal dates back to a realization that was not fully acknowledged until the First Nations Child and Family Caring Society's (the Caring Society) first publication A literature Review on Aspects of Aboriginal Child Welfare in Canada was completed in November 2002. This publication, in addition to a review of the history and the impacts of Canadian child welfare policies for Aboriginal peoples, contained over 800 annotations on articles, books, unpublished paper, reports, videos, theses and dissertations relevant to Aboriginal child welfare. The majority of resources referred to in that publication were generated by non-Aboriginal scholars, students, practitioners and/or policy makers. Very little of the voices and perspectives of Aboriginal people are captured in these academic pieces although the majority of the articles are empathetic and understanding of the impact that Canadian social policies have inflicted on Aboriginal populations.

This journal as a result attempts to level the field of knowledge generation by encouraging, promoting and privileging the "voices, perspectives and experiences" of Aboriginal people in the child welfare field. The main purpose of the First Peoples Child \& Family Review is to "reach beyond the walls of academia" to encourage individuals to publish their research, their ideas on practice, policy and education and to do so from an First Nations/Aboriginal perspective as well as to advance innovative approaches within the field of First Nations and Aboriginal child welfare.

Our first edition is very broad in scope. The first call for papers did not specifically identify a theme. Rather we choose to keep it open ended. As a result our first edition reflects a diverse set of articles which highlights some of the innovation, theory and practices occurring in the areas of Aboriginal child welfare research, policy and practice generally. As with other scholarly works, the articles submitted for publication in this journal have been peer reviewed by Aboriginal scholars, various practitioners and other community and academic "experts" who lent their knowledge and expertise to assisting in the review process.

Kathy Absolon and Cam Willett's Aboriginal Research: Berry Picking and Hunting in the 21st Centre is the first article in this edition which speaks to the importance of locating ourselves in the process of conducting research. As Aboriginal people engaged in conducting research we need to be aware of the colonialistic past which we have inherited and how the role of knowledge extraction has served to perpetuate colonialism both historically and contemporarily. Absolon and Willett stress that knowledge is about being, living and doing which implies that Aboriginal research methods are not necessarily static but imbued with action. They remind us that as Aboriginal scholars we have a responsibility to know our history and an acknowledgement that we own our own knowledge. It is implicit on Aboriginal researchers to challenge western knowledge and reality by decolonizing ourselves through our own knowledge production and constructions of Aboriginal realities. Renewal in Aboriginal research processes and methodology they state also requires strength and pride in self, 
family, community, culture, nation, identity, economy, and governance. Locating oneself as an Aboriginal researcher requires more than just doing "library research." It requires that all researchers connect to Aboriginal peoples and communities and re-examine for themselves the process of seeking knowledge that more accurately reflects and authenticates the lived realities of Aboriginal families, communities, and nations.

The second article written by myself, Marlyn Bennett, moves into the genesis of how Participatory Action Research came to be. While this piece is not specifically geared toward child welfare research, it does provide readers with a definition and an understanding of the benefits and challenges to undertaking research from a Participatory Action Research perspective.

Kelly McShane and Paul Hastings' article discusses culturally sensitive ways of conducting research in the area of child development and family practices in First Peoples' communities. They conclude that it is important that when working with First Peoples families that practitioners concentrate less on children's problems and families' difficulties but more with an emphasis on understanding the culture and taking an emic approach to building meaningful relationships with families and communities throughout all stages of the research process.

The next article, by Raven Sinclair, expounds upon Aboriginal social work education, stating that to understand the contemporary aspect of Aboriginal social work education, one must begin with an understanding of the history of European and Aboriginal relations in terms of colonization and residential schools. Sinclair identifies some of the challenges of training Aboriginal social workers from an Aboriginal epistemology and combining it with western theory and ideologies within a decolonization framework. Sinclair's piece is an important contribution to the discourse on Aboriginal child welfare as it identifies the need to revisit the core of western social work values and inject Aboriginal "intellectualism" into curriculum content.

Christopher Walmsley reviews the multitude of perspectives that represent the child protection practitioners' relationship with communities in conducting child protection work in Aboriginal communities. These multiple perspectives range from viewing the community as a victim, adversarial, participant or partner to Aboriginal communities as protectors. These views were formed depending on the level of reciprocity exhibited by the Aboriginal communities in working with the practitioners who took part in answering questions related to this study. Walmsley notes that practitioner's view Aboriginal communities as being victims or adversarial when no relationship of trust exists between the community and practitioner. The more reciprocity and mutual respect that exists between communities and child protection practitioners, the more collective community efforts there are in intervening to protect and ensure the safety and well-being of children.

Kathleen Earle Fox reports on her findings respecting neglected Native American children through her analysis of approximately 17,000 cases from the largest abuse and neglect study conducted in the United Stated, through the National Child Abuse and Neglect Data System (NCANDS). Fox cautions that the utility of NCANDS to determine levels of neglect in Indian Country is limited first, by the method of data collection because the information was collected by the state rather than tribal workers so that American Indian cases are not always included. Secondly, Fox notes that the findings of neglect in the NCANDS database are based on the perceptions of non-Native workers largely unfamiliar with Native American culture, who also hold different perspectives on what is considered to be neglect. Fox found that Native American children found to be neglected faced differential treatment compared to non-Native children when placed in care. Given these noted limitations, Fox posits that it is highly unlikely that the NCANDS results regarding the neglect of Indian children are accurate.

Kathy Bent, Wendy Josephson and Barry Kelly's article looks at the impact of an Aboriginal Enrichment program on the self-perceptions of primarily young Aboriginal mothers enrolled in a program for adolescent parents. Their research shows that the Aboriginal culture component of the program had a substantial positive effect on the self-concepts of program participants. The program not only taught the participants about aspects of their cultural identity but that culture is a basis for self-worth.

The last word belongs to Kenn Richard, the Executive Director of the Native Child and Family Services of Toronto. Kenn shares his perspective on the adoption of Aboriginal children to non-Aboriginal families. Kenn's article is unique in that it provides a perspective that is very much culled from his personal experience working with Aboriginal people in an urban setting and from witnessing first hand the negative impacts and outcomes that cross-cultural adoption imposes on Aboriginal youth living in one of Canada's largest cities. 
Readers will note that I have had quite an influence on the creation and development of this journal. There are many reasons for this. Firstly, as the director of research with the Caring Society, one of the major thrusts of my work is to ensure research capacity is built into the components of all that I undertake in my role with a national organization. I have attempted to do that here, although, by some accounts, it may appear that I am monopolizing the publication. Not only am I a contributing author but I also have a hand in all elements of this journal (from editing, writing the editorial, to stylistically designing, laying out and typing this journal). I have done this very purposefully in order to understand the publishing process from beginning to end and everything that can and will happen in between. Secondly, we have all heard the saying that "knowledge is power" but having knowledge also implies a responsibility. Our Elders teach that it is our responsibility to pass on knowledge. The Caring Society is just beginning its journey into the publishing field so it is acknowledged that we will need assistance to carry on necessitating the need to share and transfer what I have learned to another who will take over where I leave off. In the future the Caring Society hopes to hire youth who in turn will assist with mentoring others who wish to write for publication in our journal. All of this requires aspects of mentoring and mentoring is an important element in the transmission of knowledge however one must also know what is important to transmit through the mentoring process. So while it may appear that I have manipulated this publication, is was done with a very clear intention that what was learned would ultimately be shared with youth who will become involved with this publication in the future.

Over the last few months, many individuals have repeatedly enquired as to the status of this journal and many anxiously awaited its release. Undertaking the creation of a new journal is a monumental task for a one person office. However this journal would not be possible without the input of numerous people. It required a great deal of networking not only with the contributing authors but with a geographically diverse group of individuals who make up our editorial board and contacting numerous external reviewers from all across Canada. While it has taken me some time to get the inaugural issue of this journal off the ground, I am heartened by the teachings of the Elders not to rush too quickly into things. Elder Liza Mosher's teaching captures this perspective when she shared the following with Kulchyski, McCaskill and Newhouses in the book In the Words of Elders:
Aboriginal Cultures in Transition (1999):

We have to make them understand who we are. ... It's like the Original Man, he was the last one to leave the Creator's side, ... many times he's turned around and looked at the Creator and the Creator had to coax him to go. That's how slow he's walked and that's how we are, like that Original Man. We walk very slow and examine what's there and we don't jump into things right away, as soon as we jump into things right away, we try to go real fast and we fall flat on our face. ... (pp. 164-165).

I have deliberately taken it slow but the extra time that it has taken to draw together a national editorial board, find external reviewers and consult with contributing and prospective authors as well as designing and laying out this journal has been to the Caring Society's benefit but has also contributed to my own ongoing learning process and lessons learned. In the end I have collaboratively created, along with the contributing authors within this inaugural edition, a product that honours and captures diverse and important "voices and perspectives" that contribute significantly to the evolution of Indigenous knowledge creation around research, Aboriginal child welfare policy, and practice within Canada. Though I have much more yet to learn in putting together future editions of this journal, I know that it is important to continuing weaving together what is known from the past and honouring the gifts of the present which ultimately lead to the mysteries of the future. I hope that as you read this journal you are encouraged by the knowledge which the authors of this edition have shared. I hope that you are influenced enough to consider sharing your own knowledge, innovations and experiences by submitting a paper for publication in future editions of the First Peoples Child \& Family Review. By doing so you will contribute to keeping the diversity of Aboriginal culture and knowledge alive and ever contemporary.

\section{References}

Kulchyski, P., McCaskill, D. and Newhouse, D. (Eds.). (1999). In the Words of Elders: Aboriginal Cultures in Transition. Toronto: University of Toronto Press: pp. 164-165. 